\title{
Evaluation of Economic Losses due to Coccidiosis in Layer Birds in Tarai Region of Uttarakhand
}

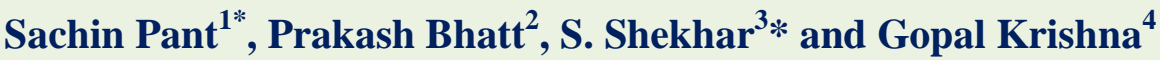 \\ ${ }^{1}$ Udham Singh Nagar Dairy Cooperative limited, Khatima, Uttarakhand, India \\ ${ }^{2}$ Department of Veterinary Clinics, C.V.A.Sc., GBPUAT, Pantnagar, India \\ ${ }^{3}$ Veterinary Science., Krishi Vigyan Kendra, Koderma, Jharkhand, India \\ ${ }^{4}$ Department of Animal Husbandry, Himachal Pradesh, India
}

*Corresponding author

\section{A B S T R A C T}

\section{Keywords \\ Economic impact, \\ Coccidiosis, \\ Subclinical form \\ Article Info \\ Accepted: \\ 04 June 2018 \\ Available Online: \\ 10 July 2018}

Economic impact assessment due to coccidiosis was conducted in commercial layer farms during the period from June, 2015 to January, 2016. A total of 6 poultry farms which were screened for coccidiosis, 3 layer farms (L1, L2 and L3) were found to be positive and among these 3 farms, in farm L1 and L2 no subclinical form of coccidiosis was recorded with maximum economic loss being due to mortality followed by chemotherapy and chemoprophylaxis. While in farm L3, no chemoprophylactic drug was used with maximum loss due to chemotherapy cost followed by loss in egg production and mortality. Vaccination was not used in any of the layer flocks.

\section{Introduction}

In India, poultry production exists in both traditional extensive system of backyard farming as well as modern intensive system. Ministry of Food Processing Industries mentioned that, both organized and unorganized poultry sectors contribute $70 \%$ and $30 \%$, respectively, with chicken followed by ducks being the two most popular species dominating with more than $99 \%$ to the total poultry production, while other avian species like guinea fowl, geese, quails, pea fowl, etc. account for less than 1\% (Jadhav and Nikam, 2014). Inspite of the fact that coccidiosis is probably the most frequently reported disease in chicken worldwide (Biggs, 1982), there are many hurdles in arriving at a trusted figure for the specific financial losses and thus there are only occasional reports on the economic losses of poultry due to coccidiosis (Oyekole, 1984; Braunius, 1987; Graat, 1996). The estimation of economic losses by different countries differs because of the variability in factors included in the study and very few estimates are available for India. 


\section{Materials and Methods}

\section{Type of bird considered for the calculation}

Commercial layer flocks positive for poultry coccidiosis were considered for the assessment of economic loss.

\section{Data collection}

Records of the commercial poultry farms were analysed for the value of major inputs and outputs and were supplemented with questionnaire designed to obtain additional information from poultry farmers.

\section{Lifespan of birds}

Lifespan for commercial layer life span was taken as 72 weeks.

\section{Overhead cost}

Overhead cost of bird was assumed as per prevailing rates. It consisted of electricity, management and labour cost excluding the cost of chick and feed.

Market value of day old chick (DOC), poultry meat and eggs

The market price of chicks for commercial layer and egg were taken as per prevailing rates mentioned in farm records and were further supplemented by NECC (National Egg Coordination Committee) and www.Poultrybazaar.com.

\section{Anti coccidial vaccine}

The cost of each dose was taken as per prevailing rates mentioned in farm records (If used).

\section{Feed requirement and cost}

The cumulative feed requirement $(\mathrm{kg} / \mathrm{bird})$ for commercial layer was taken. Cost of feed was taken as per prevailing rates mentioned in farm records.

\section{Economic models}

The model developed by Williams (1999) to estimate the losses due to poultry coccidiosis were used in the study with slight modification as required.

\section{Commercial layer}

The major economic parameters which were estimated for commercial layer were

\section{Vaccination}

Birds kept in deep litter system for first 16 weeks and then transferred to the cage system in those cases birds are to be vaccinated and the model for calculation was:

$$
\begin{aligned}
& \mathrm{CV}(\text { cost of vaccination })=\mathrm{NBV} \times \mathrm{CV} \\
& \mathrm{NBV}=\text { no. of birds vaccinated } \\
& \mathrm{CV}=\text { cost of vaccine per dose }
\end{aligned}
$$

\section{Chemoprophylaxis}

Commercial layer reared under cage system do not require prophylaxis. But, in some of the farms birds also maintained in deep litter system where chemoprophylaxis is required and the economic model for commercial layer was:

TCCP (total cost of chemoprophylaxis) = $\mathrm{N} \times \mathrm{CFR} \times \mathrm{MU} \times \mathrm{CM}$

$\mathrm{N}=$ no. of birds placed

$\mathrm{CFR}=$ cumulative feed requirement for each bird (ton)

$\mathrm{MU}=$ medicine used, $\mathrm{kg} / \mathrm{ton}$ of feed

$\mathrm{CM}=$ cost of medicine $(\mathrm{Rs} / \mathrm{kg})$

\section{Chemotherapy}

The occurrence of clinical coccidiosis in commercial layer is not uncommon. The economic model used was: 
TCCT (total cost of chemotherapy) = $\mathrm{NTB} \times \mathrm{RW} \times 2 *(\mathrm{M} 1+\mathrm{M} 2) \times \mathrm{CM}$

$\mathrm{NTB}=$ number of treated birds

$\mathrm{RW}=$ requirement of water, $\mathrm{L} /$ day/bird

M1 = medicine mixed with water in first half of treatment, $\mathrm{kg} / \mathrm{L}$

M2 = medicine mixed with water in second half of treatment, $\mathrm{kg} / \mathrm{L}$

$\mathrm{CM}=$ cost of medicine in $\mathrm{Rs} / \mathrm{kg}$

*Modified as per the drug used

\section{Egg production loss}

The model for egg production loss was:

TLEP (Total loss due to reduced egg production $)=[\mathrm{NEH} \times \mathrm{CEH}]+[\mathrm{NET} \times \mathrm{CET}]$

$\mathrm{NEH}=$ no. of hatching egg loss

$\mathrm{CEH}=$ cost of single hatching egg

NET $=$ no. of table egg loss

$\mathrm{CET}=$ cost of single table egg

\section{Loss due to mortality}

The model for economic calculation was:

$\mathrm{LM}$ (loss due to mortality) = BDLx [VCL+CFL+OC]

$\mathrm{BDL}=$ no. of layer birds died

VCL $=$ value of layer chick

$\mathrm{CFL}=$ cost of cumulative feed

\section{Results and Discussion}

A total of 6 layer farms were screened during the study period out of which 3 farms were confirmed to be positive for coccidiosis and to evaluate the economic loss in the positive farm, a questionnaire survey was done which was further supplemented with the farm records available (Table 1). Based on these economic loss occurred in the farm was calculated. The details of the layer farms are given in Table 2.
Name of farm: Poultry farm (L1)

1. TCCP (total cost of chemoprophylaxis) = $\mathrm{N} \times \mathrm{CFR} \times \mathrm{MU} \times \mathrm{CM}$

$$
\begin{aligned}
& =1200 \times 0.00085 \times 0.5 \times 300 \\
& =\operatorname{Rs} 153
\end{aligned}
$$

2. TCCT (total cost of chemotherapy) = $\mathrm{NTB} \times \mathrm{RW} \times 5 \times(\mathrm{M} 1+\mathrm{M} 2) \times \mathrm{CM}$

$$
\begin{aligned}
& =1100 \times 0.3 \times 5 \times 0.001 \times 1325 \\
& =\operatorname{Rs} 2186
\end{aligned}
$$

3. $\mathrm{LM}$ (loss due to mortality) = $\mathrm{BD} \times$ $(\mathrm{VC}+\mathrm{CCF}+\mathrm{OC})$

$$
\begin{aligned}
& =110 \times(22+17.50+3.00) \\
& =\operatorname{Rs} 4675
\end{aligned}
$$

Total economic loss assessed = $153+2186+4675=$ Rs 7014

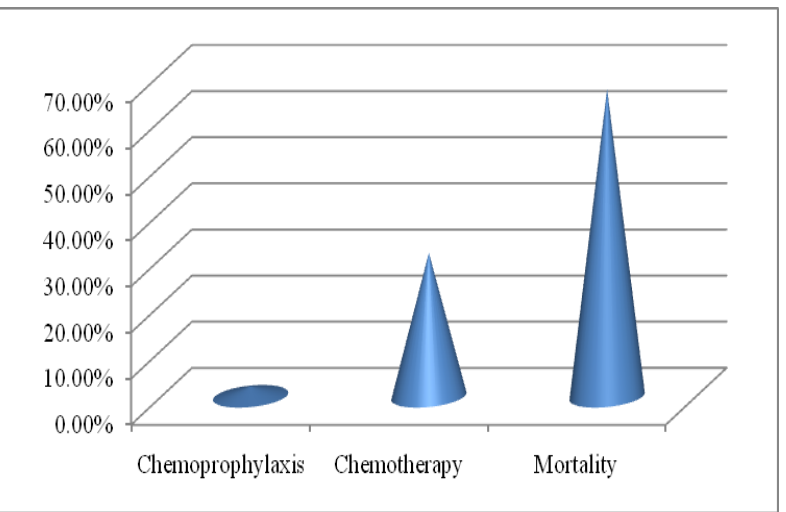

Name of farm: Poultry farm (L2)

1. TCCP (total cost of chemoprophylaxis) = $\mathrm{N} \times \mathrm{CFR} \times \mathrm{MU} \times \mathrm{CM}$

$$
\begin{aligned}
& =600 \times 0.001 \times 0.5 \times 200 \\
& =\operatorname{Rs} 60
\end{aligned}
$$

2. TCCT (total cost of chemotherapy) = $\mathrm{NTB} \times \mathrm{RW} \times 5 \times(\mathrm{M} 1+\mathrm{M} 2) \times \mathrm{CM}$ 


$$
\begin{aligned}
& =536 \times 0.350 \times 5 \times 0.002 \times 1350 \\
& =\operatorname{Rs} 2533
\end{aligned}
$$

3. $\mathrm{LM}$ (loss due to mortality) $=\mathrm{BD} \times$ $(\mathrm{VC}+\mathrm{CCF}+\mathrm{OC})$

$$
\begin{aligned}
& =84 \times(25+18+3.50) \\
& =\text { Rs } 3906
\end{aligned}
$$

Total economic loss assessed = $60+2533+3906=$ Rs 6499

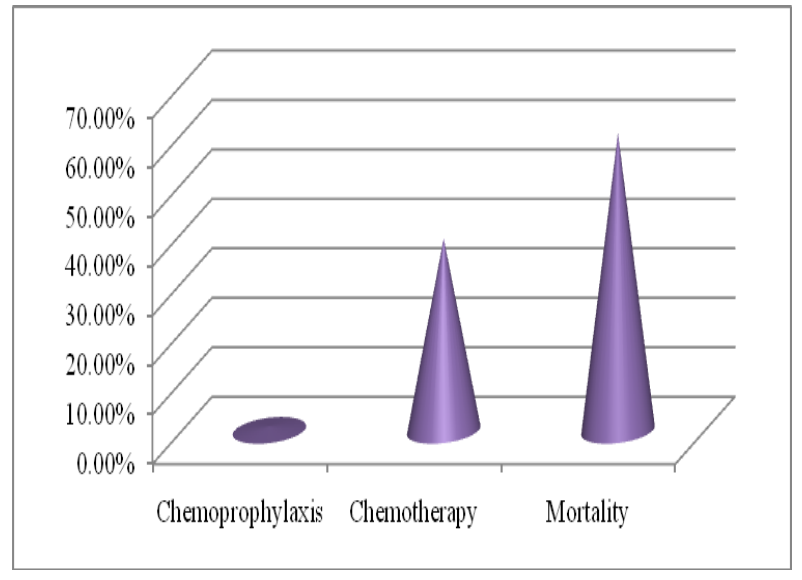

Name of the farm: Poultry farm (L3)

TCCP (total cost of chemoprophylaxis) = $\mathrm{N} \times \mathrm{CFR} \times \mathrm{MU} \times \mathrm{CM}$

$$
\begin{aligned}
& =4100 \times 0.012 \times 0 \\
& =\operatorname{Rs} 0
\end{aligned}
$$

2. TCCT (total cost of chemotherapy) = $\mathrm{NTB} \times \mathrm{RW} \times 5 \times(\mathrm{M} 1+\mathrm{M} 2) \times \mathrm{CM}$

$$
\begin{aligned}
& =4040 \times 0.825 \times 5 \times 0.001 \times 1470 \\
& =\text { Rs } 24,498
\end{aligned}
$$

3. $\mathrm{LM}$ (loss due to mortality) = $\mathrm{BD} \times$ $(\mathrm{VC}+\mathrm{CCF}+\mathrm{OC})$

$$
\begin{aligned}
& =70 \times(23+15.25+33.75) \\
& =\text { Rs } 5040
\end{aligned}
$$

4. TLEP (total loss due to reduced egg production $)=[\mathrm{NEH} \times \mathrm{CEH}]+[\mathrm{NET} \times \mathrm{CET}]$

$$
\begin{aligned}
& =0+[4030 \times 3.25] \\
& =\operatorname{Rs~} 13,098
\end{aligned}
$$

Total economic loss assessed = $0+24498+5040+13098=$ Rs 42,636

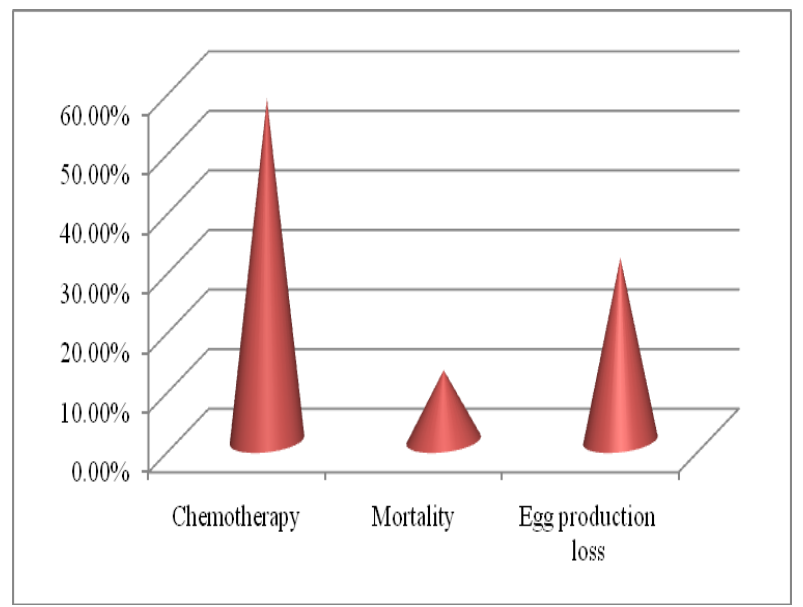

Table.1 Major parameters considered for estimation

\begin{tabular}{|l|c|}
\hline S. no. & Parameters for Layer \\
\hline $\mathbf{1 .}$ & Chemoprophylaxis cost \\
\hline $\mathbf{2 .}$ & Cost of chemotherapy \\
\hline $\mathbf{3 .}$ & Loss due to mortality \\
\hline $\mathbf{4 .}$ & Egg production loss \\
\hline $\mathbf{5 .}$ & Vaccination cost \\
\hline
\end{tabular}


Table.2 Data collected from commercial layer flock

\begin{tabular}{|c|c|c|c|}
\hline Name of the Farm & $\begin{array}{c}\text { Poultry Farm } \\
\text { (Uttarkashi) }\end{array}$ & $\begin{array}{l}\text { Poultry Farm } \\
\text { (Pantnagar) }\end{array}$ & $\begin{array}{l}\text { Poultry Farm } \\
\text { (Khatima) }\end{array}$ \\
\hline Code no. & Farm L1 & Farm L2 & Farm L3 \\
\hline Flock Strength & 1200 & 600 & 4100 \\
\hline $\begin{array}{c}\text { CFR } \\
\text { (Tonne/bird) }\end{array}$ & 0.00085 & 0.0010 & .011 \\
\hline $\begin{array}{c}\text { Chemoprophylactic } \\
\text { Drug Used }\end{array}$ & $\begin{array}{l}\text { Nicarbazine+ } \\
\text { Maduramycin }\end{array}$ & DOT & - \\
\hline $\begin{array}{c}\text { Dose } \\
\text { (Kg/ton of feed) }\end{array}$ & 0.500 & 0.500 & - \\
\hline $\begin{array}{c}\text { Cost of Medicine } \\
(\mathrm{Rs} / \mathrm{kg})\end{array}$ & 300 & 200 & - \\
\hline No. of Treated Birds & 1100 & 536 & 4040 \\
\hline $\begin{array}{l}\text { Water Requirement } \\
\text { (Lit/day/bird) }\end{array}$ & 0.300 & 0.350 & 0.825 \\
\hline Total Mortality & 110 & 84 & 70 \\
\hline $\begin{array}{c}\text { Chemotherapeutic } \\
\text { Drug Used }\end{array}$ & Amprolium & Amprolium & $\begin{array}{l}\text { Amprolium+ } \\
\text { sulfaquinoxaline }\end{array}$ \\
\hline $\begin{array}{l}\text { Cost of Medicine } \\
\text { (Rs/kg) }\end{array}$ & 1325 & 1350 & 1470 \\
\hline No. of table egg loss & - & - & 4030 \\
\hline $\begin{array}{c}\text { Cost of single table } \\
\text { egg (Rs) }\end{array}$ & - & - & 3.25 \\
\hline $\begin{array}{c}\text { Value of layer chick } \\
\text { (Rs) }\end{array}$ & 22 & 25 & 23 \\
\hline $\begin{array}{l}\text { Overhead Cost } \\
\text { (Rs) }\end{array}$ & 3.00 & 3.50 & 15.25 \\
\hline $\begin{array}{c}\text { Cost of cumulative } \\
\text { feed } \\
\text { (Rs) }\end{array}$ & 17.50 & 18.00 & 33.75 \\
\hline
\end{tabular}

Table.3 Assessment of economic loss in commercial layer flock

\begin{tabular}{|c|c|c|c|}
\hline & \multicolumn{3}{|c|}{ Farm Code } \\
\hline $\begin{array}{c}\text { Economic Parameters } \\
\text { (Rs) }\end{array}$ & $\mathbf{L 1}$ & $\mathbf{L 2}$ & $\mathbf{L 3}$ \\
\hline Vaccination & - & - & - \\
\hline Prophylaxis & $153(2.18 \%)$ & $60(0.92 \%)$ & - \\
\hline Chemotherapy & $2186(31.16 \%)$ & $2533(38.9 \%)$ & $24498(57.45 \%)$ \\
\hline Mortality & $4675(66.65 \%)$ & $3906(60.1 \%)$ & $5040(11.82 \%)$ \\
\hline Egg production loss & - & - & $13,098(30.72 \%)$ \\
\hline Total loss & $\mathbf{7 , 0 1 4}$ & $\mathbf{6 , 4 9 9}$ & $\mathbf{4 2 , 6 3 6}$ \\
\hline
\end{tabular}


In the present study, it was observed that in case of layers in farm L1 and L2, no subclinical form of coccidiosis and maximum loss occurred due to mortality followed by chemotherapy and prophylaxis. While, in farm L3 no prophylactic drug was mixed in feed and majority of loss was due to cost of chemotherapy, followed by loss in egg production and mortality. No vaccination was administered in any of the layer flocks. The further details are represented in Table 3.

Kinung' hi et al., (2004) studied that coccidiosis caused losses were due to mortalities, coccidiostat costs, reduced weight gain and market value and reduced egg production in layers. In case of farm L1 and L2 in which no subclinical form was observed maximum loss occurred due to mortality and this coincides with the observation made by Kinung' hi et al., (2004) and the reason could be the presence of more clinical form as compared to other farms. While in case of L3 the present study contraindicated the observation made by Bera $e t$ al., (2010) that maximum losses occur due to chemoprophylaxis cost and loss of egg production. This variation may be due to the fact that in the studied farm (L3) no chemoprophylactic drug was administered and also due to the fluctuating costs of different commodities from those assumed by Bera et al., (2010).

In conclusion, based on the assessment of economic impact due to coccidiosis in commercial layer farms it was observed that layer farms incurred significant economic losses with major losses due to mortality, chemotherapy and chemoprophylaxis in farms in which no subclinical form of coccidiosis was recorded (L1 and L2). While in farm L3, subclinical coccidiosis was observed with major loss due to chemotherapeutic cost, loss in egg production and mortality. Prevention of coccidiosis via vaccination was not followed in any of the coccidiosis affected farms.

\section{References}

Jadhav B. N. and Nikam, S. V. (2014). Study of seasonal incidence of chicken coccidiosis in Gangapur and Vaijapur tehsil of Aurangabad district in Maharashtra. International Journal of Applied ScienceResearch and Review. 1(3): 93-97

Bera, A. K., Bhattacharya, D., Pan, D., Dhara, A., Kumar, S. and Das, S. K. (2010). Evaluation of economic losses due to coccidiosis in poultry industry in India. Agri. Eco. Res. Rev., 23: 91-96

Biggs, P. M. (1982). The world of poultry disease. Avian Pathol., 11: 281-300

Oyekole, O. D. (1984). A mathematical model for assessing the economic effects of disease in broiler chicken flocks. Preventive Vet. Med., 3: 151-158

Braunius, W. W. (1987). Some aspects of epidemiology and control of coccidiosis in broilers. Thesis, Ph.D. University of Utrecht, the Netherlands

Graat, E. A. M. (1996). Epidemiology Eimeria acervulina infections in broiler: An integrated approach. Thesis, Ph.D. University of Wageningen, the Netherlands

Williams, R. B. (1999). A compartmentalized model for the estimation of the cost of coccidiosis to the world's chicken production industry. Int. J. Parasitol., 29: 1209-1229

Kinung'hi, S. M., Tilahun, G., Hafez, M. and Woldemeskel, M. (2004). Assesment of economic impact caused by poultry coccidiosis in small and large scale poultry farms in Debre Zeit, Ethiopia. Int. J. Poult Sci., 3(11): 715-718.

\section{How to cite this article:}

Sachin Pant, Prakash Bhatt, S. Shekhar and Gopal Krishna. 2018. Evaluation of Economic Losses due to Coccidiosis in Layer Birds in Tarai Region of Uttarakhand. Int.J.Curr.Microbiol.App.Sci. 7(07): 381386. doi: https://doi.org/10.20546/ijcmas.2018.707.047 